\title{
Participatory approach on water management for food security vis-à-vis sustainable agriculture
}

\begin{abstract}
The per-capita availability of cultivable land as well as water is going to be stagnated, wherein irrigation is the only key factor leading to increased crop and water productivity through increasing cropping intensities and incorporating more profitable cropping patterns accessible to the small holders. Indian agriculture has got resilience with introduction of fertilizers and irrigation responsive high yielding varieties (HYVs) during mid-70s'. Wherein, water is considered as major indicator of agricultural growth for livelihood, environmental and socio-economic security of the country. The integrated management of water resources could only be possible through adoption of efficient and optimum use of irrigation water, which could only be ensured by judicious and economic use of irrigation potential whatsoever created to increase crop production. The integrated water resources management also includes the concept of rain-water management that has got an immense important on the way to develop the rain-fed farming system. In the areas of medium to heavy rainfall, there is ample scope of tapping excess rain water through suitable water harvesting structures constructed for this purpose for its subsequent uses as irrigation or to apply life saving irrigation to the crops which should also come under the purview of water management for crop production. Farmers' participatory based action research programme on adoption of water saving technologies so far generated for increasing crop production could be useful for maintaining sustainable growth and development of agriculture. The on-farm studies in these aspects showed that there were positive impacts of irrigation water on sustainable agricultural development as regards to increased crop productivity, cropping intensity, input use efficiency, farmers' income, employment generation and poverty alleviation from disadvantaged rural sects. The availability of irrigation facilities enabled the farmers to raise at least one extra crop a year with consequent implications for household food security with higher yields of the crops grown along with employment opportunity per unit of arable land.
\end{abstract}

Keywords: potential, crop production, farmers, water, agriculture, employment
Volume 6 Issue 2 - 2018

\author{
Zaman A, Swaminathan MS \\ School of Agriculture, Centurion University of Management \& \\ Technology, India
}

Correspondence: Zaman A, School of Agriculture, Centurion University of Management \& Technology, Paralakhemundi-76I

21 I, Odisha, India, Email profazaman@gmail.com

Received: November 22, 2017 | Published: March 08, 2018
Abbreviations: DVC, damodar valley corporation; PVC, polyvinyl chloride; NREGS, national rural employment guarantee scheme; HYVs, high yielding varieties.

\section{Introduction}

Irrigation potential is major indicator of agricultural growth that summarizes its strong positive correlation with poverty alleviation. The availability of cultivable land is exhausted, wherein irrigation helps in increasing crop and water productivity through increasing cropping intensities providing more profitable cropping patterns accessible to the small holders. The integrated management of water resources could only be possible through adoption of efficient and optimum use of irrigation water, which could only be ensured by judicious and economic use of irrigation potential whatsoever created to increase crop production. The integrated water resources management also includes the concept of rain-water management that has got an immense important on the way to develop the rainfed farming system. Previously, rain-fed agriculture was associated primarily with conservational land treatments to check soil erosion and land degradation. But in the areas of medium to heavy rainfall, there is ample scope of tapping excess rain water through suitable water harvesting structures constructed for this purpose for its subsequent uses as irrigation or to apply lifesaving irrigation to the crops which should also come under the purview of water management for crop production. The basic objective of the Act is to enhance livelihood security in rural areas by providing at least 100 days of guaranteed wage employment in a financial year to every household whose adult members volunteer to do unskilled manual work. This work guarantee can also serve other objectives: generating productive assets, protecting the environment, empowering rural women, reducing ruralurban migration and fostering social equity, among others that were considered under National Rural Employment Guarantee Scheme (NREGS) 2005 of the Government of India.

The objectives of participatory research on water management are as follows:

i. To establish linkage between irrigation water management and poverty; 
ii. To assess the role of irrigation management in poverty alleviation, the linkages and pathways through which irrigation contributes in poverty alleviation and the magnitude of anti-poverty impacts of irrigation and to find out key-determinants factors to enhancing anti-poverty impacts of irrigation.

\section{Methodologies}

In a word, a number of water management technologies for field crops have been developed over years to enhance agricultural production. The area of crop(s) under irrigation was also increased substantially. The irrigation potential was created at the cost of huge amount of national exchequer. But there is still a large gap between the irrigation potential created and utilized. Likewise the gap between technologies generation and adoption are also being widening at threshold level. That stands the water management technologies developed so far were not also being practiced at the actual users' end. There are gaps in the existing system, which acts as constraints on adoption of water management technologies.

To address the problems and to bridge the gap, the constraints analysis on issues and priorities of water management would be helpful at end users levels on adoption of water-efficient management practices for growing field crop(s). Particularly wherein the necessity of food for ever-growing population will require irrigated agriculture and more than $80 \%$ of available water is being used as irrigation.

Water resource management is a multidisciplinary activity, managing irrigation water will need agronomy and crop husbandry, efficient methods and system of irrigation needs soils scientists and engineers. Effective minimization of wastage of water used for irrigation and application of right quantity of water at right time will be the key to successful management of this crucial resource.

More than $98 \%$ of the irrigated lands are under the coverage of surface irrigation where more than $50 \%$ of water as considered as wastages. The pressurized irrigation (drip and sprinkler) methods have become the tool of water saving technologies to get rid of such situations.

A series of field experiments on field crops were conducted to find out the optimum water and nutritional requirement of different filed crops and was under operation up to 1985 . The project then shifted to Research Farm at Memari under Old Alluvial Zone in 1985 to carry out water management research on different field crops to cater the needs of Damodar Valley Corporation (DVC) command and continued to work up to 1995 . The project was again shifted and started its functioning from the headquarter of the Viswavidyalaya at Central Research Farm, Gayeshpur to carry out research work on water management of different field crops, including fruits, vegetables and flowers grown under different deep tube well command in the district of Nadia, West Bengal under assured supply of water in New Alluvial Zone since 1995.

\section{Results and discussion}

A large number of site specific and cost effective water management technologies as regards to suitable method and optimum scheduling of irrigation for various field crops, conjunctive use of rain/surface and ground water for crop cultivation and water economy, implication of drainage in monsoon season to restore the soil workability condition for sustainable crop production, some unorthodox measures for applying water through polyvinyl chloride (PVC) pipes to avoid application and conveyance losses, on-plot conservation of rain water and subsequent uses in crop production programmes were developed in the controlled condition experimental field trials and appeared to be fruitful for achieving higher yields, saving a significant quantity of valuable water, a greater employment opportunity and higher farm family income. With a view to adopt these proven water management technologies in the actual farming condition, a number of interventions or its modified forms as applicable in the specific farming situation were tried in the fields dominated by the resource poor farmers for adoption with a view to exploit the valuable water resources for remunerative crop yields and also to elevate the socio-economic status of the farming community.

The technologies are found accepted and adopted by the farmers in their fields are as follows:

The results of the experimentation got relevancy particularly in installing small-scale irrigation system based on farmers' participatory approach for sustainable crop production for maintaining sustainable growth and development of agriculture. Although there is a difference in the objectives of water management where there is abundant availability of water from continuous flow connected with perennial sources or lakes and rivers and that of from restricted or limited supply from collection of excess rain through water harvesting structures. The former is associated with to obtain as much as yield of crop per unit area under water application and later is associated with increasing productivity of crop per unit of water application even under rainwater recycling and its effective management for the purpose of irrigation.

Researchers and planners have studied in depth the impacts of irrigation water on crop productivity, cropping intensity, input use, farmers' income and employment generation and poverty alleviation. The availability of irrigation facilities has enabled the farmers to raise nearly one extra crop a year with consequent implications for household food security with higher yields of the crops grown along with labour employment per unit of land. The opportunities of rural development has thus been assigned with possibilities of water management interventions through adoption of National Rural Employment Guarantee Scheme of The Government of India creating and assuring at least 100 man days for single farmer a year keeping pace with rural development.

\section{on-farm water management}

Adoption of proven water management technologies ensures to achieve high water productivity in agriculture. Trist ${ }^{1}$ considered the irrigation system as a complex socio-technical phenomenon that involved interaction between physical, environmental and technological parameters in the process of adoption. Whyte ${ }^{2}$ considered the participatory action research as more effective and communicative measures in the developmental processes. Korten ${ }^{3}$ described the participatory action research as a method of merging both developmental intervention and research activities as an effort to involve the users in systemic process of change to make the sociotechnical system more effective and efficient. Xianjun ${ }^{4}$ reported that on-farm irrigation management and irrigation service thereby improved by involving farmers in water management practices and introducing an acceptable water-saving irrigation schedule for growing crops and increasing agricultural production. Pramanick et 
al. ${ }^{5}$ described the results of on-going 5-year demonstration that onfarm participatory field trials brought positive improvements towards better water use efficiency following the recommended methods of water management practices in the farmer's field in DVC command in West Bengal. Dhindwal et al. ${ }^{6}$ also reported the success story of on-farm water management. Zaman et al. $^{7}$ stated the adoption of rainwater harvesting with existing ponds ensured more water resource availability and utilization in coastal saline region of Sagar Island. Under this stated situations, 4 (four) proven water management technologies were considered for demonstration in farmers field for growing crops to combat water scarcity ensuring effective water resource utilization includes rain-water harvesting, recycling for lifesaving irrigation application, growing second crop after rainy season harvest with selection of crops and its varieties having less water requirement.

\section{Conclusion}

Proper planning for effective water utilization is need of the hour, as stated above would assist to increase productivity and come forward to meet ever increasing demand of food grains in sustainable agriculture. The network of media (radio, television, newspaper and journal-magazine) and information technology have to play vital to disseminate the proper education on water use water-saving technologies generated for agricultural purpose including pressurized irrigation system (drip, sprinkler and subsurface). The proven and need-based technologies developed in the field should acts as practical tool and media should act as communication channel forecasting the alarming situations out of water. The planners, researchers and policy makers should come into hand-to-hand to bridge the gap between technology development in the field and adoption in actual field condition. As because more than $90 \%$ of such generated technologies, so far, at the cost of heavy national exchequer, have not been implemented by actual users. Posters, brochures, banners, hoardings, exhibitions, seminars and symposiums are to be organized more to create effective awareness campaigning towards more and more peoples' participation and that is the only the key to save the nations from anticipated devastated situations that would come out of water scarcity. The water managers, researchers and policy makers will have a crucial role to play for creating efficient strategies for equitable sharing of water minimizing possible conflicts and unintended consequences.

\section{Acknowledgements}

The author acknowledges the assistance of water management team of BCKV (State Agricultural University, West Bengal during his tenure as Chief Scientist (2003-2012). The participatory approach of water management technology adoption is only the way to achieve the goal of food security and in the way of sustainable agriculture in the country.

\section{Conflict of interest}

There is no conflict of interest on publishing the article.

\section{References}

1. Trist E. The evaluation of socio-technical system: a conceptual framework and action research programme. Toronto. 1981.p. 1-59.

2. Whyte WF editor. Participatory action research. Newbury Park, California, London \& New Delhi, Sage Publications, Inc. 123. Thousand Oaks, CA, US: Sage Publications; 1991. p. 1-123.

3. Kurten D. Community organization and rural development: a learning process approach. Public administrative review. 1980;40(5):481-515.

4. Xianjun C. Introduction of water saving irrigation scheduling through improved water delivery: a case study from China. Proc of ICID/FAO Workshop, Rome, Water Report; 1996.

5. Pramanick M, Mallick S. Farmer's participatory approach for improvement of present status of irrigation water utilisation in DVC canal Command. Proc of ICID/FAO Workshop, Rome, Water Report; 1996. $558 \mathrm{p}$.

6. Dhindwal AS, Poonia SR. On-farm water management-a success story. Intensive Agriculture. 1994;32(1-2):37-38.

7. Zaman A, Gayen A. Mitigation of water crisis and growing crops in lean period by rainwater harvesting through concreted rooftops and household ponds in Sagar Island. Current Agril Res J. 2013;1(2):87-91 